\title{
Microbial Study on NiO - CuO Nano Particles by Grinding Technique
}

S Ramakrishnan ( $\nabla$ rkphysics91@gmail.com )

Madura College

R. Vaishnavi

Madura College

S. Ramakrishnan

Madura College

M. Revathi

Madura College

S. Rajakarthihan

Thiagarajar College

\section{Research Article}

Keywords: NiO, CuO, Grinding, Antimicrobial, Anti fungal

Posted Date: July 14th, 2021

DOl: https://doi.org/10.21203/rs.3.rs-683355/v1

License: (c) (i) This work is licensed under a Creative Commons Attribution 4.0 International License. Read Full License 


\section{Abstract}

One of the biggest concerns around the world seems to be the fight against bacteria and fungi. This major challenge can be overcome with the addition of a combination of metal and metal oxides. Metal oxide nanoparticles have emerged as effective antimicrobial and anti-fungal agents. In this work, A Grinding technique has been used to synthesize $\mathrm{NiO}$ - $\mathrm{CuO}$ nanoparticles. Nanoparticles were characterized using X-ray powder diffraction (XRD) analysis which confirmed the formation of all the phases, Fourier Transform-Infrared Spectroscopy (FTIR), UV-Visible Absorption Spectroscopy and Scanning Electron Microscope (SEM) analysis were showed the vibrational structure, optical and uniformity of particle size of the nanoparticles. Bacterial and fungal growth study was confirmed by the disc diffusion method. The prepared nanoparticles showed detrimental effects against Streptococcus, Staphylococcus aureus (bacterial strains), and Aspergillus Niger (fungal strains). A concentrationdependent growth inhibition effect of nanoparticles on both bacteria and fungi was observed. The prepared composites were better active in both bacteria and fungies.

\section{Introduction}

Nanotechnology is one of the most active fields of modern materials science study. Based on certain qualities such as size, distribution, and shape, nanoparticles exhibit new or better properties. Because of their small size, they have different properties than the bulk form of the same material, allowing for various new biosensor innovations. It is also being used in medicine to help with diagnostics, drug delivery, and treatment development for a variety of diseases and disorders. [1]. Viruses, fungi, bacteria, and parasites have been responsible for a large number of deaths in recent decades as a result of spreadable diseases. Our immune system can protect us from a wide range of pathogens. Infections, on the other hand, can be spread from bacteria to human bodies through natural orifices cells, causing tissue damage. Drug resistance is impeding the treatment of infectious diseases, necessitating the development of novel medicines that can overcome drug resistance. New medical agents, such as antibody-based therapies and metal oxide nanoparticles, have been developed as a result of these factors for the treatment of communicable diseases.

Metal oxide nanoparticles can exhibit unique physical and chemical properties due to their limited size and a high density of corner or edge surface sites. Particle size is expected to influence the important groups of basic properties in any material. As the particle size decreases, the increasing number of surface and interface atoms generates stress/strain and concomitant structural perturbations. Metals have been used for centuries as bactericidal and bacteriostatic agents. Among those used is silver, copper, zinc, gold and nickel each with different properties and spectrum of activity [2].

Nickel oxide is the chemical compound with the formula $\mathrm{NiO}$. It is an important transition metal oxide with cubic lattice structure. Due to their special structures and properties, NiO nanoparticles have been widely used in various fields, such as photoelectric, recording materials, catalysts, sensors, ceramic materials and anti medicine for bacterial pathogens etc. High purity and ultra fine nickel metal powder is 
a key component of many different materials that is used to manufacture a wide range of end-use products such as catalysts, magnetic devices, powder metallurgical components and gas sensing [3].

Copper oxide ( $\mathrm{CuO})$ is the useful metal oxide and has so many applications in different areas. It is a $p$ type metal oxide semiconductor with promising applications in solar energy conversion and catalysis. It can be mixed easily with other metal oxide to provide the composites with unique physio-chemical properties. Also, these nanoparticles have high surface areas and unusual crystalline structures to give CuO NPs with antimicrobial activity that is dose dependent Studying quantum confinement effects or modifying the behaviour of the direct forbidden band gap is very challenging. The unique property of $\mathrm{CuO}$ is it acts as a good semiconductor. Semiconductor materials have been particularly interesting because of their great practical importance in electronic and optoelectronic devices [4].

The interaction of combined metal oxides with nano level composites was the breaking of chemical bonds and the creation of new ones, which causes change in biological property of the composites. The changes of properties create an energetic novel fascinating by surrounding the metal oxide in another metal oxide matrix. The presence of double metal particles could fruitful improves the optical and structural properties of the composites. Changes in the optical and biological properties of composites were considered mainly in microbial applications. In this study, we have confirmed that the metal oxide composites could develop more efficiency in bacteria and funnies.

\section{Materials And Methods}

Nickel oxide and Copper oxide are the materials to be used in this work. The purchased $\mathrm{NiO}$ nanoparticles were absorbed into copper oxide matrix during grinding (equal weight) using mortars and pestles of 3 hours. The crystalline phase was determined by XRD using CuKa as radiation source. The Vibrational characteristics were studied using FTIR spectroscope. The optical characteristics are studied using UVVis and PL. The morphology of the prepared nano particles were confirmed by SEM. The elemental analysis was done by EDAX. The biological activity like antimicrobial and anti fungal was carried out using disc diffusion method.

The disk diffusion method is a test of the antibiotic sensitivity of bacteria. It uses antibiotic discs to test the extent to which bacteria are affected by those antibiotics. In this test, wafers containing antibiotics are placed on an agar plate where bacteria have been placed, and the plate is left to incubate. If an antibiotic stops the bacteria from growing or kills the bacteria, there will be an area around the wafer where the bacteria have not grown enough to be visible. This is called a zone of inhibition. The agar plate surface is inoculated by spreading a volume of the microbial inoculums over the entire agar surface. Desired concentration of filter paper discs is placed on the surface and which are incubated in suitable condition depending upon the test microorganism. The antimicrobial agent diffuses in the agar medium and inhibits the growth of the microbial strain tested [5].

\section{Results}


Fig 1 shows the combined XRD pattern of $\mathrm{NiO}$ and copper oxide ( $\mathrm{NiO}$ - $\mathrm{CuO}$ ). It shows the crystalline nature of copper oxide does not change, when added with nickel oxide It is clear that no other characteristic peak due to any impurities and sharp peaks are present in the pattern, indicating that the prepared samples are of high purity and crystallinity [6].The marked peaks are corresponding to the crystalline planes of composites and $2 \theta$ comparison was tabulated and as shown in table 1 . The average grain size of composite was found to be $25 \mathrm{~nm}$ by using the Debye-Scherer formula.

Fig 2 represents the FTIR pattern of NiO-CuO nano composites; the absorption bond at 423 is associated to $\mathrm{Ni}-\mathrm{O}$ vibration bond. The broad absorption band in the region $430-498 \mathrm{~cm}^{-1}$ is assigned to $\mathrm{Ni}-\mathrm{O}$ stretching vibration mode [7]. The broadness of the band indicates the nano crystalline nature of the samples. The observed copper bands in nano particles at $418.55 \mathrm{~cm}^{-1}$ and $607.58 \mathrm{~cm}^{-1}$ are assigned to the stretching vibrations of Cu-O. The stretching frequency of bulk CuO is $491 \mathrm{~cm}^{-1}$ [8]. The combined pattern shows some shift in the wave number as well as change in the intensity of peaks as compared to pure CuO.

The UV-visible absorption spectra of $\mathrm{NiO}-\mathrm{CuO}$ nano composites were recorded at room temperature are given in Fig. 3. it shows that the sample absorbs more light energy in the higher wave length and less light energy in the lower wave length region. The first sharper peak at around $349 \mathrm{~nm}$ is associated to the absorption peak of $\mathrm{Ni}$ nano particles, Undoped $\mathrm{CuO}$ nanostructures exhibit band edge absorption peak at $416 \mathrm{~nm}$ which is blue shifted with NiO doping. This means that the levels of the energy band were affected by the Rayleigh scattering from the embedded nickel nano particles in $\mathrm{CuO}$.

The SEM images of the synthesized $\mathrm{NiO}$ - CuO samples clearly indicate the formation of hierarchical nanostructures as shown in figure 4 [9]. From SEM micrographs that the synthesized nano-composites are to form of shape-like aggregated nano-clusters due to vander waals force between particles. EDAX spectrum, of NiO- CuO was shown in the Fig.5. Spectrum plot not only identifies the elements corresponding to each of its peaks, but the type of X-ray to which it corresponds as well. The dried powder of the sample was analyzed and their peaks have confirmed the presence of Copper, Oxygen, and nickel atoms.

The biological activity of the composite, such as antibacterial and antifungal activity, was investigated using disc diffusion methods, as shown in figures 6,7 , and 8 . Only at greater concentrations does the produced nano particle demonstrate a beneficial antibacterial activity against bacteria. When NiO was mixed with $\mathrm{CuO}$, the antibacterial action was enhanced. Antifungal tests yielded similar results. In this investigation, we found that the composites were more effective at inhibiting gram-positive bacteria such as streptococcus than Staphylococcus. The diameter of the inhibitory zone created around the wells, as well as the values, are given in tables 2 and 3 for bacteria and fungus, respectively.

\section{Discussion}


The cubic structure of $\mathrm{CuO}$ was does not modified with the presence of $\mathrm{NiO}$ and they are agreed with JCPDS and literal surveys. As the Cu content in the system of nano composites grows, the observed peak intensity from XRD linked to Ni drops and the peak intensity of $\mathrm{Cu}$ increases. It is important to mention here that, the effective decrease in crystallite sizes of composites could be attributed to conversion of some phases is changes via a synergistic mechanism. The presence of dual in the oxide mixtures valances should modify their textural, morphological and biological properties.

The addition of $\mathrm{NiO}$ to $\mathrm{CuO}$, vibrational wave numbers was shifted to lower wave numbers and merged, which shows the copper oxide was uniformly distributed in nickel oxide. Due to the conjugation loss and molecular interaction between composites, the changes are observed. The reduced form of oxygen and strong localization of electron interaction between the composites are the reason of merging wave numbers [10]. Furthermore, NiO doping results in the widening of the absorption peak towards visible region. It is observed that nickel oxide doping has effectively enhanced the visible light absorption capability of $\mathrm{CuO}$ nanostructures which might be potential for visible light photo catalysis and biological applications. The values of absorption wave length were found to decrease, this means that the $\mathrm{NiO}$ creates defects in CuO composites.

The SEM image confirms the prepared nano particles are uniform distribution in surface and the particles are segregated in the surface of the samples is spherical and rod shape in morphology. The tension and energy of the samples was very low is the reason for particles are separated in surface.

Normally, Gram positive bacteria are industrial strains of a microorganism that may be found in a variety of environments in nature, as well as an occasional pathogen of humans, plants, and animals that can cause disease but is unlikely to be a severe concern under normal circumstances. The $\mathrm{Cu}$ and $\mathrm{O}$ ions are easily occupied when nickel oxide is mixed with copper oxide matrix, allowing them to engage in antibacterial action. One of the causes for increased bacterial activity against the bacterial pathogen is the particle size of the sample [11]. The antibacterial activity of the nano composites appears to have increased when the surface-to-volume ratio rose due to the decrease in nano particle size, as seen in the table.

In this study, $\mathrm{NiO}$ - CuO nano composites outperformed individual nanoparticles in terms of antibacterial activity. However, as previously said, it is critical to discover the fundamental physicochemical features of nano metal oxides that regulate antibacterial activity and cytotoxicity to bacteria's cells. If these particles are to have widespread biomedical applications, it is critical to examine their contribution in terms of size, shape, and morphology. We expect to see such nanocomposites used as surface disinfectants first, because their stability will allow for long-term storage and activity.

The nano composites were found to have strong antifungal efficacy against Aspergillus Niger at varied molar concentrations. The efficacy of nano composite treatment rose when the concentration was increased from $50 \mathrm{~g}$ to $500 \mathrm{~g}$. various antifungal effects may, however, be due to the fungi's different growth morphologies. In this investigation, the composites outperformed the prepared ones in terms of 
antifungal activity. Because of their unique features, such as huge surface area, the nano composites in our study exhibit a significant increase in antibacterial activity [12].

\section{Conclusions}

The samples were prepared using grinding technique. From XRD the composites were found to be good in crystallinity and the particle size was found to decrease upon the addition of nickel oxide. The FTIR shows that vibrational bonds are slightly altered. Ultra Violet spectroscopy reveals that the band gap increases with addition of nickel in copper oxide. SEM and EDAX analysis confirm the morphology and that the elements are in good agglomeration. From the biological study the prepared composites show significant effects against both gram positive bacteria and fungi. The prepared composites were better activity in both bacteria and fungies.

\section{Declarations}

All manuscripts must contain the following sections under the heading 'Declarations'.

\section{Funding}

No funds, grants, or other support was received.

\section{Conflicts of interest/Competing interests}

The authors have no conflicts of interest to declare that are relevant to the content of this article.

\section{Availability of data and material}

Not applicable

\section{Code availability}

Not applicable

\section{Ethics approval}

- Research does not involving any Human Participants and/or Animals

- The manuscript should not be submitted to more than one journal for simultaneous consideration.

- The submitted work should be original and should not have been published elsewhere in any form or language (partially or in full), unless the new work concerns an expansion of previous work.

\section{Consent to participate}

Yes 


\section{Consent for publication}

Yes

\section{References}

[1] Rejith, S., Krishnan, C. (2013)Optical characterizations of Zn-doped CuO nanoparticles. Sci. Acta Xaver $, 4,91$.

[2] Magdalane, C.M,. Kaviyarasu, K. et.al. (2016) Photocatalytic activity of binary metal oxide nanocomposites of $\mathrm{CeO}_{2} / \mathrm{CdO}$ nanospheres: Investigation of optical and antimicrobial activity. J. Photochem. Photobiol. B Biol. 163, 77-86.

[3] Gondala, M.A., Saleh, A.T. et. al. (2012) Synthesis of nickel oxide nanoparticlesusing pulsed laser ablation in liquids and their optical characterization Applied Surface Science, 258, 6982-6986.

[4] Bish, D., Post, J. (1989) Modern Powder Diffraction. Reviews in Mineralogy. 20,369.

[5] Balouiri, M., Sadiki, M., Ibnsouda, S. K. (2016) Methods for in vitro evaluating antimicrobial activity: A review. Journal of Pharmaceutical Analysis. 6(2), 71-79.

[6] Rahdar, A., Aliahmad, M. et. al. (2017) CuO-NiO Nano composites: Synthesis, Characterization, and Cytotoxicity evaluation. Nano medicine Research Journal. 2, 78-86.

[7] Brondon, D., Kaplan, W. D. (2008) Micro structural Characterization of Materials, John- Wiley and Sons Publications. 550.

[8] Qiao, H., Wei, Z., Yang, H., Zhu, L., Yan, X. J Nanomater 2009, 795928, 1.

[9] Gholivand, M.B., Heydari, H.et.al. (2015) Nano structured CuO/ PANI composite as super capacitor electrode material. Materials Science in Semiconductor Processing. 30, 157-161.

[10] Suresh, S., Karthikeyan, S., Saravanan, P., Jayamoorthy, K. (2016) Comparison of antibacterial and antifungal activities of 5-amino-2-mercaptobenzimidazole and functionalized $\mathrm{NiO}$ nanoparticles. Karbala International Journal of Modern Science. 2 (3), 188-195

[11] Chang, Y.N., Zhang, M., Xia, .L, et al. (2012) The toxic effects and mechanisms of $\mathrm{CuO}$ and ZnO nanoparticles. Materials. 5,2850-2871.

[12] Xu, M., Fujita, D., Kajiwara, S., et al. (2010) Contribution of physicochemical characteristics of nanooxides to cytotoxicity. Biomaterials.31, 8022-031.

\section{Tables}


Table 1 Comparison of $2 \theta$ Values NiO - CuO composites

\begin{tabular}{|lllll|}
\hline S.No & $\begin{array}{l}\text { Theoretical 2 } \boldsymbol{\theta} \text { Values } \\
\text { (degree) }\end{array}$ & $\begin{array}{l}\text { Experimental 2 } \boldsymbol{\theta} \text { Values } \\
\text { (degree) }\end{array}$ & $\begin{array}{l}\text { Miller } \\
\text { Planes }\end{array}$ & Samples \\
\hline 1 & 35.49 & 35.48 & 002 & $\mathrm{CuO}$ \\
\hline 2 & 37.25 & 37.72 & 111 & $\mathrm{NiO}$ \\
\hline 3 & 38.99 & 38.81 & 111 & $\mathrm{CuO}$ \\
\hline 4 & 43.28 & 43.45 & 200 & $\mathrm{NiO}$ \\
\hline 5 & 48.73 & 48.90 & 202 & $\mathrm{CuO}$ \\
\hline 6 & 62.87 & 63.20 & 220 & $\mathrm{NiO}$ \\
\hline & & & & \\
\hline
\end{tabular}

Table 2 Antimicrobial Activity of the samples treated against the gram positive bacteria

\begin{tabular}{|c|c|c|c|c|c|c|}
\hline \multirow[t]{3}{*}{ S.No } & \multirow[t]{3}{*}{ Samples } & \multicolumn{5}{|c|}{$\begin{array}{l}\text { ZONE OF INHIBITION IN DIAMETER } \\
\text { (in } \mathrm{mm} \text { ) }\end{array}$} \\
\hline & & \multicolumn{3}{|c|}{$\begin{array}{l}\text { Streptococcus } \\
(100 \mathrm{mg} / \mathrm{ml})\end{array}$} & \multicolumn{2}{|c|}{ Staphylococcus aureus $(100 \mathrm{mg} / \mathrm{ml})$} \\
\hline & & Control & Standard & Sample & Standard & Sample \\
\hline 1 & Pure CuO & NZ & 21 & 8 & 24 & 11 \\
\hline 2 & Pure NiO & NZ & 21 & 12 & 24 & 11 \\
\hline 3 & $\mathrm{NiO}-\mathrm{CuO}$ & NZ & 21 & 20 & 24 & 14 \\
\hline
\end{tabular}

Table 3 Antifungal activity of the samples treated against the fungal pathogens

\begin{tabular}{|lllll|}
\hline S.No & Samples & \multicolumn{2}{l|}{$\begin{array}{l}\text { ZONE OF INHIBITION IN DIAMETER } \\
(\mathrm{mm})\end{array}$} \\
\cline { 3 - 5 } & & Control & Standard & Sample $(500 \mu \mathrm{g} / \mathrm{ml})$ \\
\hline 1 & Pure CuO & $\mathrm{NZ}$ & 15 & 11 \\
\hline 2 & Pure NiO & $\mathrm{NZ}$ & 18 & 12 \\
\hline 3 & $\mathrm{NiO}-\mathrm{CuO}$ & $\mathrm{NZ}$ & 14 & 13 \\
\hline
\end{tabular}

\section{Figures}




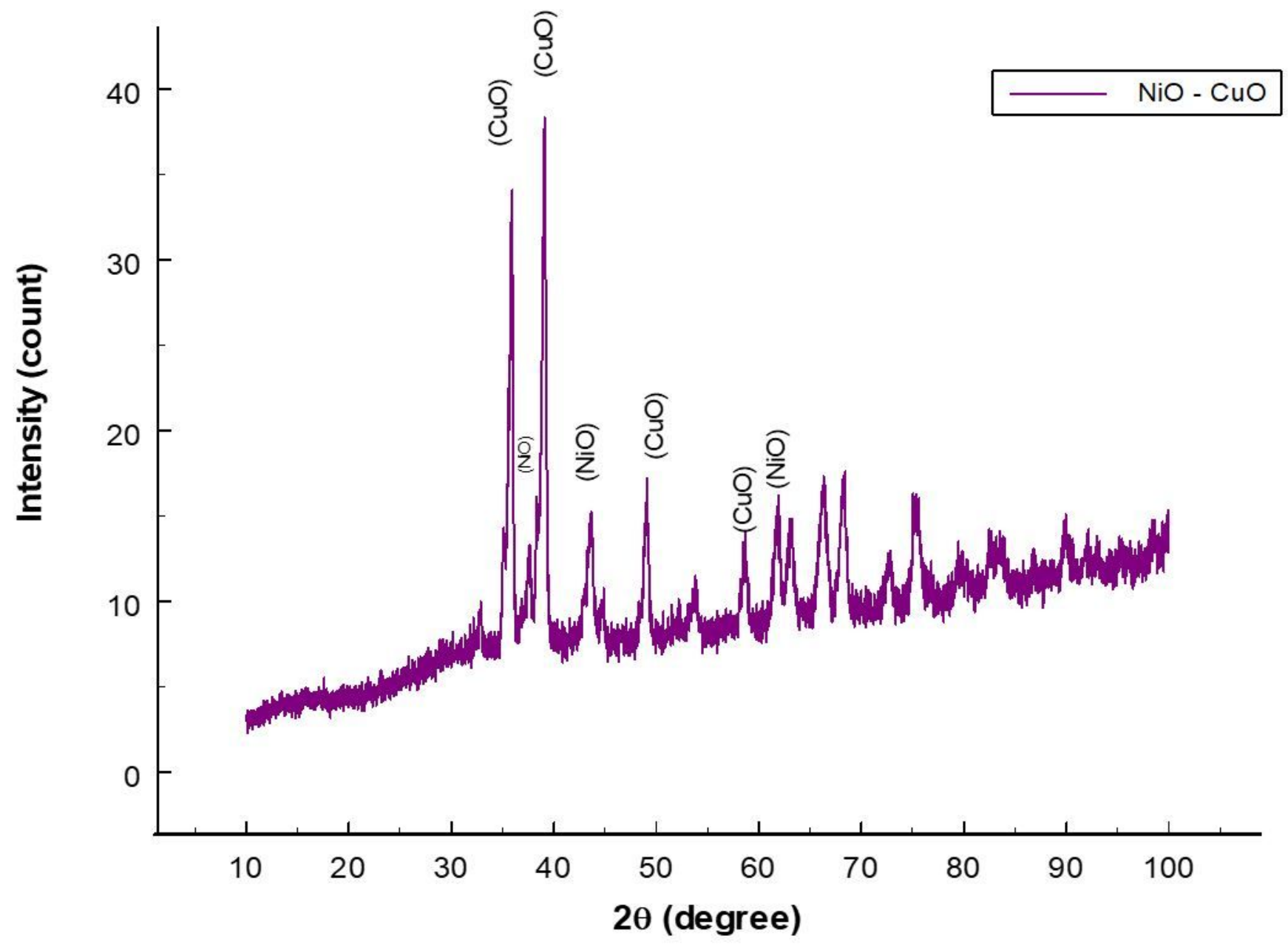

Figure 1

XRD Spectrum of pure $\mathrm{NiO}-\mathrm{CuO}$ 


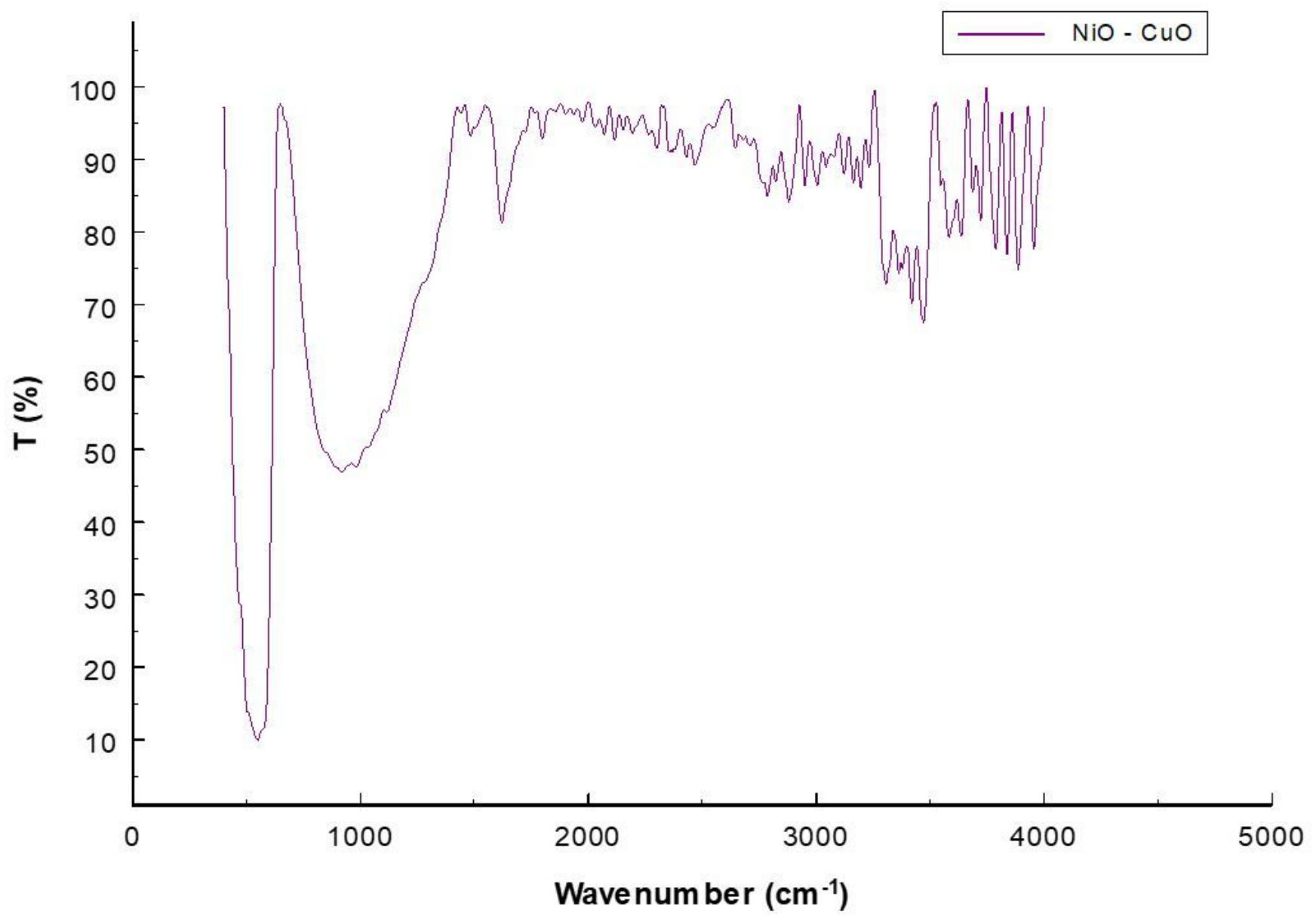

Figure 2

FTIR Spectrum of pure $\mathrm{NiO}-\mathrm{CuO}$ 


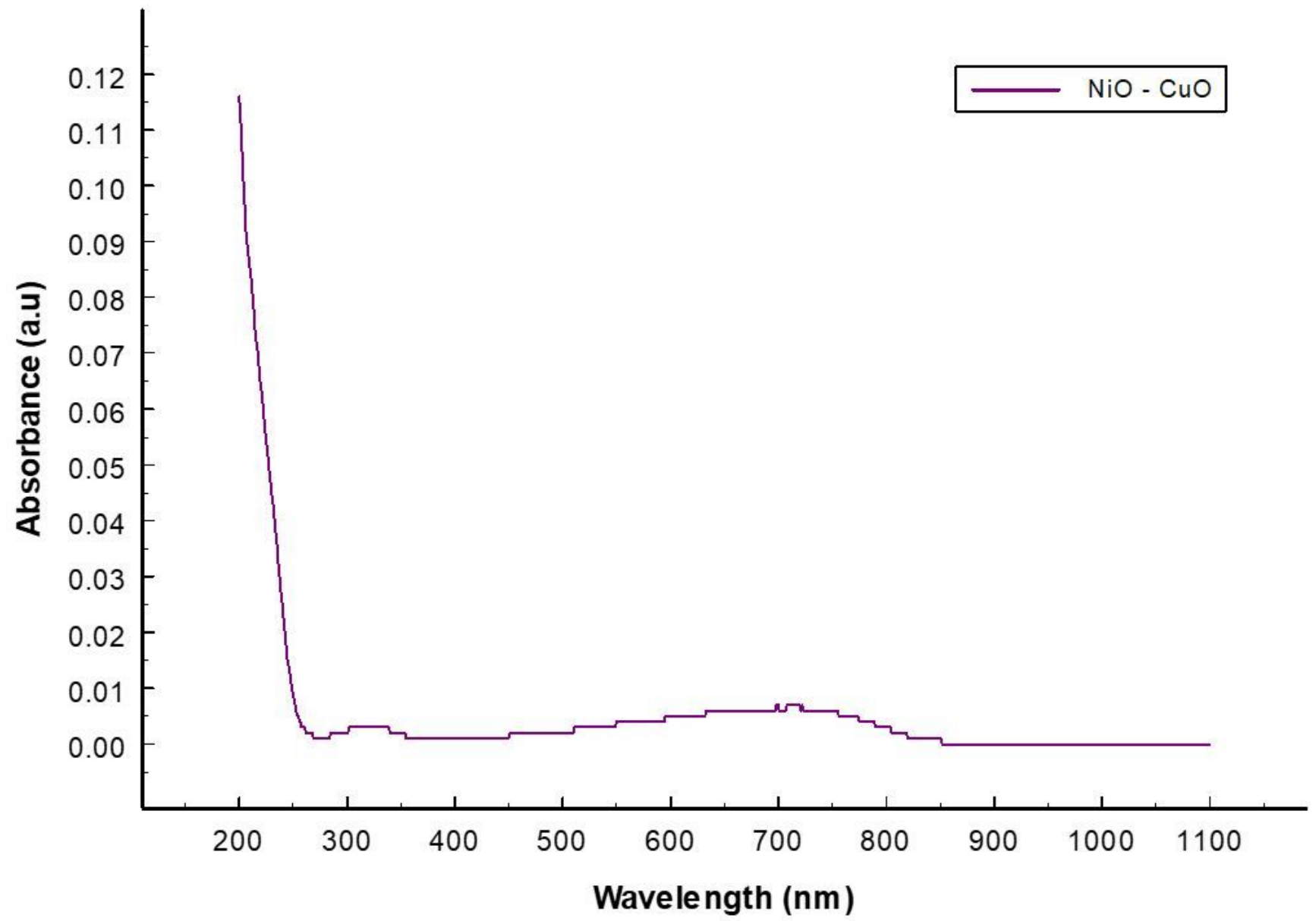

Figure 3

UV Spectrum of pure $\mathrm{NiO}-\mathrm{CuO}$
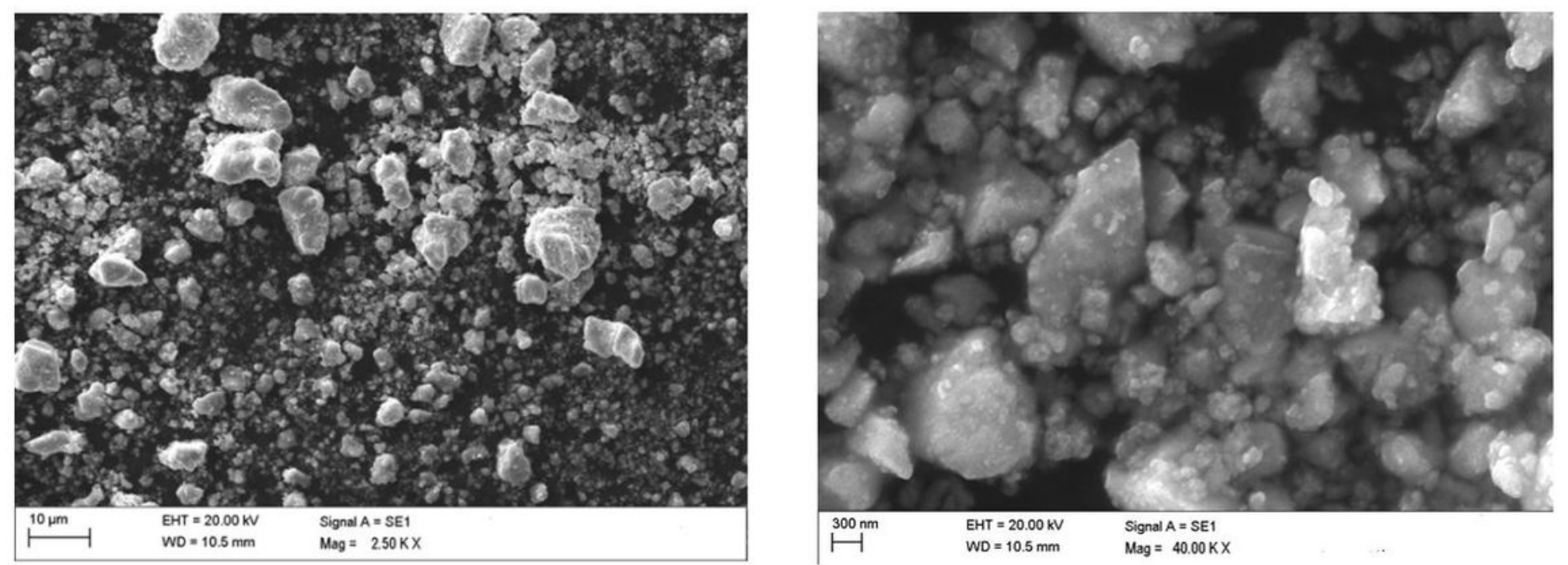

Figure 4

SEM image of Pure $\mathrm{NiO}-\mathrm{CuO}$ 


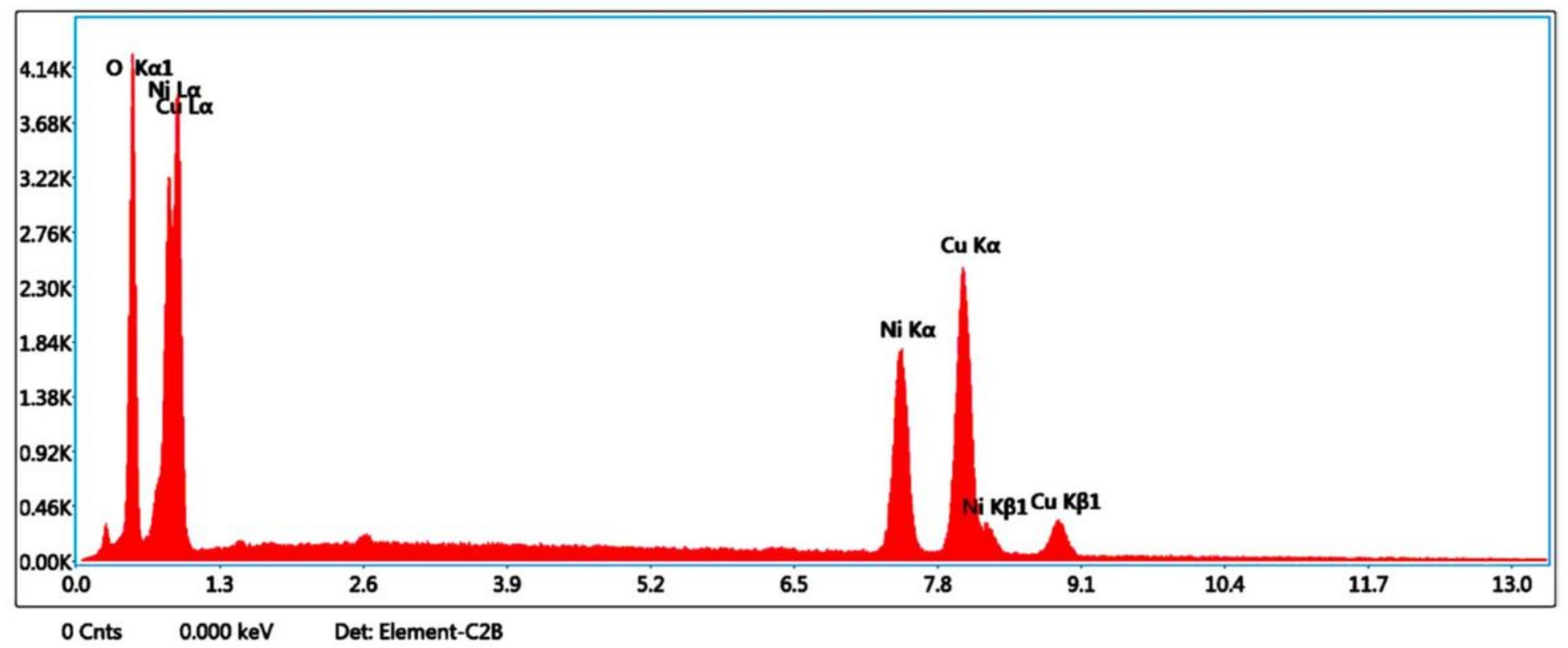

Figure 5

EDAX Spectrum of Pure NiO - CuO
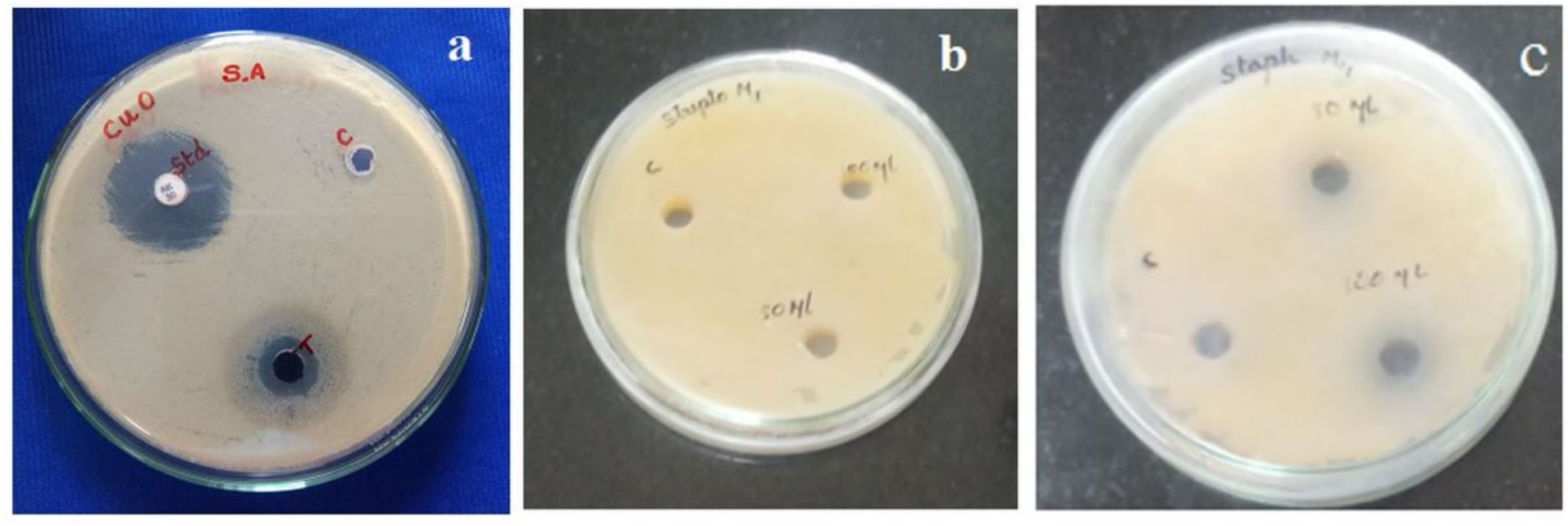

Figure 6

Antimicrobial study against Staphylococcus aureus of a) Pure $\mathrm{CuO}$ b) Pure $\mathrm{NiO}$ C) $\mathrm{NiO}-\mathrm{CuO}$ 

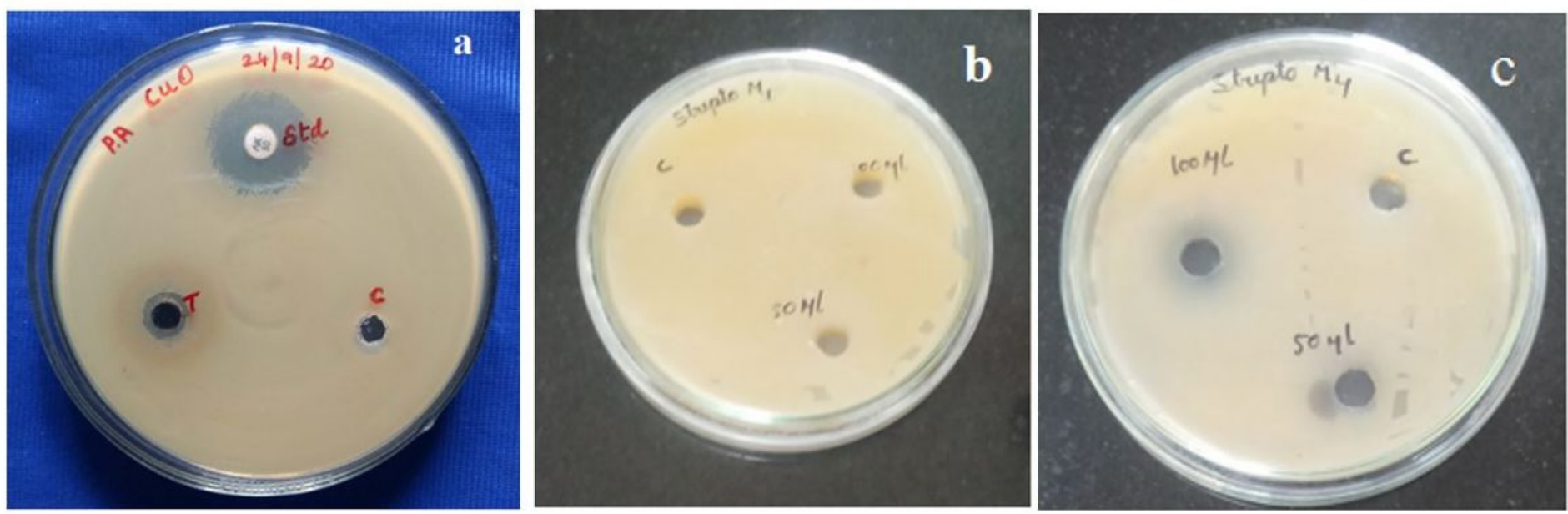

\section{Figure 7}

Antimicrobial study against Streptococcus of a) Pure $\mathrm{CuO}$ b) Pure $\mathrm{NiO}$ C) $\mathrm{NiO}$ - CuO
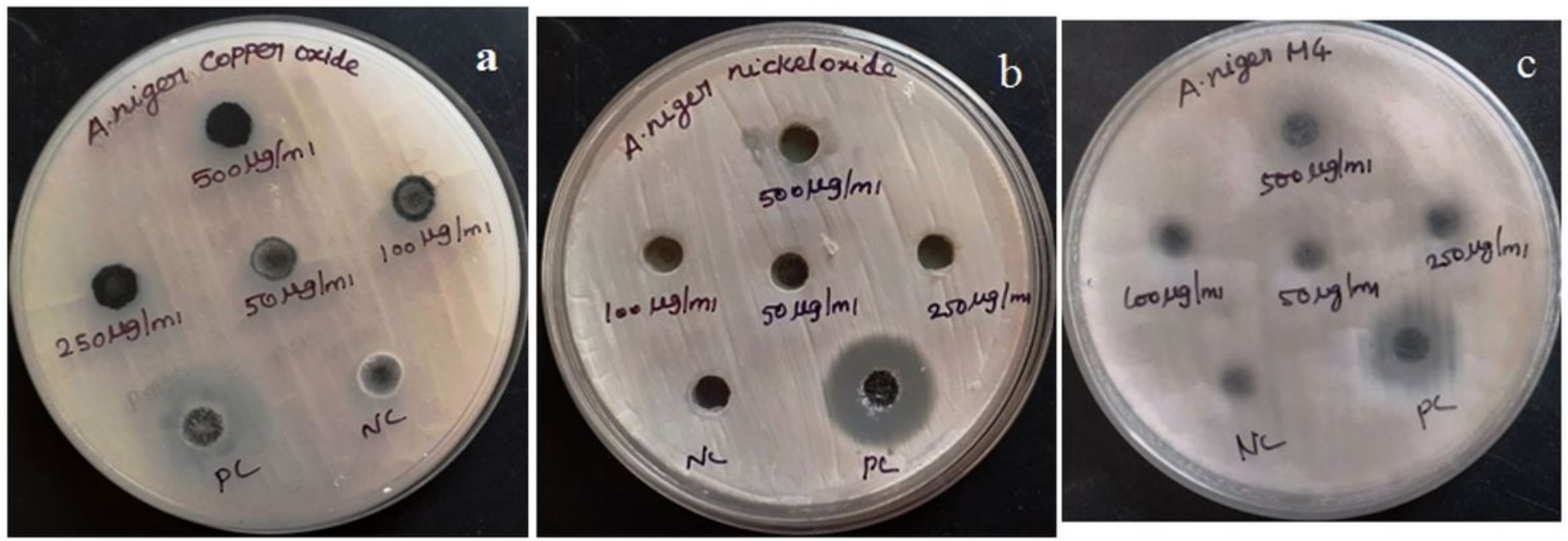

Figure 8

Anti Fungi study against Aspergillus Niger of a) Pure $\mathrm{CuO}$ b) Pure $\mathrm{NiO}$ C) $\mathrm{NiO}-\mathrm{CuO}$ 